Volume 3, Nomor 2, 2020, hlm. 133-148

P-ISSN: 2622-2280 | E-ISSN: 2622-4658

https://ejurnal.iiq.ac.id/index.php/alfanar

DOI: 10.33511/alfanar.v3n2.133-148

\title{
Dimensi Sosial dalam Tafsir Sufistik
}

(Penafsiran QS. Al-Fatihah [1]: 1 Oleh KH. Soleh Darat)

\author{
Aty Munshihah \\ Fakultas Ushuluddin dan Pemikiran Islam \\ UIN Sunan Kalijaga Yogyakarta \\ atymunshihah@gmail.com
}

\begin{abstract}
Faid ar-Rahmān fi Tarjama Tafsīr Kalam Malik ad-Dayyān by KH. Shaleh Darat land has been read from a sufitic dimension. However, there is actually a social dimension that has escaped the previous readings. Therefore, this study provides a new perspective in reading the interpretation of KH. Soleh Darat especially in QS. al-Fatihah [1]: 1. This type of research is classified as library research. By using a contextual-sufistic approach, the results of this study are; first, the two characteristics that are in the basmalah pronunciation not only show attributes for Allah but also humans; second, basmalah have social value in it, $h$ al it is illustrated by their compassionate nature that also must be inculcated in ourselves humans themselves (both physical and spiritual) and then applied to the fellow beings by sharing sustenance and mutual reminded in his favor; third, the practice of social life as a symbol that there is God as the Creator.
\end{abstract}

Keywords: KH. Saleh Darat, Sufistik, Basmalah, Social Values

\begin{abstract}
Abstrak
Faị̣ ar-Rahmān fì Tarjama Tafsīr Kalam Malik ad-Dayyān karya KH. Shaleh Darat selama ini dibaca dari dimensi sufistik. Akan tetapi, sebenarnya terdapat dimensi sosial yang luput dari pembacaan-pembacaan sebelumnya. Oleh karena itu, penelitian ini memberikan perspektif baru dalam membaca penafsiran KH. Soleh Darat khususnya pada QS. al-Fatihah [1]: 1. Adapun jenis penelitian ini tergolong kepada penelitian kepustakaan (library research). Dengan menggunakan pendekatan sufistik-kontekstual maka hasil dari penelitian ini adalah; pertama, dua sifat yang ada dalam lafal basmalah tidak hanya menunjukkan sifat bagi Allah namun juga manusia; kedua, basmalah memiliki nilai sosial di dalamnya, hal itu digambarkan dengan adanya sifat belas kasih yang juga harus ditanamkan pada diri manusia sendiri (baik jasmani maupun ruhani) lalu diterapkan kepada sesama makhluk dengan cara berbagi rezeki dan saling mengingatkan dalam kebaikan; ketiga, praktek kehidupan sosial tersebut sebagai simbol bahwa adanya Allah sebagai Sang Pencipta.
\end{abstract}

Kata Kunci: KH. Saleh Darat: Sufistik: Basmalah: Nilai Sosial 
Dimensi Sosial dalam Tafsir Sufistik

(Penafsiran QS. Al-Fatihah [1]: 1 Oleh KH. Soleh Darat)

\section{PENDAHULUAN}

QS. Al-Fatihah [1]: 1 yang berbunyi "bismillāhirrahmānirrahīm" sering disebut juga dengan lafal basmalah. Tanpa disadari, lafal ini sering diungkapkan oleh sebagian orang khususnya di Indonesia. Terbukti dengan adanya kejadian-kejadian di acara televisi, dapat kita temukan aktor/aktris yang juga mengucapkan lafal bismillāh walaupun bukan beragama Islam. Meski seolah hanya mengikuti naskah yang ada, akan tetapi ini membuktikan bahwa lafal bismillāh telah dikonsumsi dan tidak hanya dipraktekkan oleh orang muslim saja akan tetapi juga nonmuslim. Selain diterapkan pada lisan, lafal basmalah juga telah membooming dalam segi tulisan. Hal itu dapat kita saksikan pada sticker-sticker bertuliskan bismillāhirrahmānirrahīm yang ditempelkan di dinding, atau bahkan kendaraan seperti mobil, motor, dan lain sebagainya.

Pemaknaan lafal basmalah pun telah banyak dilakukan. Selain karena menjadi salah satu ayat Al-Qur'an yakni ayat pertama pada surah al-Fatihah, basmalah juga banyak menyimpan makna rahasia di baliknya. Sehinggga banyak mufassir telah mengorek hal itu. Sebagaimana pendapat salah seorang mufassir bahwa Al-Qur'an dengan terdiri dari 114 surah dan 6.236 ayat itu semuanya tersimpul dalam surah al-Fātihah, selanjutnya ada pendapat lagi yang mengungkapkan bahwa surah al-Fātihah telah tersimpul dalam lafal bismillāhirrahmānirrahīm, hingga akhirnya ada pendapat yang mengungkapkan bahwa bismillāhirrahmānirrahīm tersimpul pada huruf ba'-nya bismillāh. ${ }^{1}$

Penelitian kali ini merujuk pada salah satu mufassir lokal Indonesia yakni KH. Soleh Darat. Salah satu mufassir abad ke-19 yang berada di pulau Jawa (Semarang) yang memiliki ciri khas penulisan tafsir dengan corak sufistik. Hal itu, menjadi sebuah ketertarikan peneliti, karena butuhnya pemaknaan yang tidak hanya beroperasi pada makna literal ayat namun juga makna bathiniyahnya. Oleh sebab itu, adanya pemaknaan yang lebih mendalam berharap dapat ditemukan dengan menggunakan tafsir bercorak sufistik ini, agar tercapainya tujuan penulis.

Penelitian yang membahas tentang makna bismillāh sebagai objek kajian memang telah ada sebelumnya, mislanya "Nilai-Nilai Optimisme dalam Isti'ādzah dan Basmalah (Studi Tafsir Ar-Razi) yang ditulis oleh Yuzaidi dan Winda Sari yang memandang bismillāh dengan sudut pandang filsafat dalam tafsirnya Ar-Razi, sehingga ditemukanlah bahwa bismillāh merupakan salah satu lafal yang dapat memicu hadirnya energi optimis dalam diri seseorang ketika mengucapkannya. Tidak sekedar diamalkan di lisan saja akan tetapi juga ditanamkan di dalam hati.

Selain penelitian yang telah disebutkan di atas, penulis juga menemukan beberapa penelitian sebelumnya. Adapun penelitian sebelumnya itu lebih cenderung kepada pemaknaan salah satu huruf basmalah, ${ }^{2}$ hukum pembacaan basmalah dalam shalat, ${ }^{3}$

\footnotetext{
${ }^{1}$ Hamka. Tafsir Al-Azhar. Jil. 1. (Singapura: Pustaka Nasioanal PTE LTD, 1982), h. 62

${ }^{2}$ Sholahuddin Ashani, "Tafsir Huruf Ba' Dalam Basmalah; Pendekatan Tafsir Isyari Najmuddin Al-Kubra" 6. 1 (2020), h. 16.

3 Azhari, Fathurrahman Azhari, "Ikhtilaf Ulama Tentang Kedudukan Basmalah Dalam AlFatihah Dibaca Ketika Shalat," Syariah Jurnal Hukum dan Pemikiran 15, no. 2 (2016).
} 
ataupun living Qur'an dengan basmalah. ${ }^{4}$ Sedangkan penelitian ini akan membahas pemaknaan bismillāh menurut KH. Soleh Darat dalam tafsirnya Faid ar-Rahmān $f i$ Tarjama Tafsīr Kalam Malik ad-Dayyān yang cenderung bercorak sufistik (isyari). Sehingga akan menunjukkan bahwa pelafalan basmalah yang kian menggema sebagai simbol bahwa Sang Pencipta benar adanya, karena di dalamnya terdapat nilai-nilai sosial yang mengingatkan manusia berkedudukan sebagai hamba dan juga makhluk sosial.

Corak sufistik ini menunjukkan adanya makna zahir dan bațin pada setiap teksnya. Hal yang menarik dari penafsiran sufistik mendorong para pengkaji tafsir dalam berdialetika dengan teks yang tidak hanya dari makna zahir (tekstual), namun merasuk lebih dalam lagi untuk mengurai dan mengungkap makna bațin dari setiap teks. ${ }^{5}$ Corak sufistik ini cenderung mengungkapkan isyarat makna bațin sesuai dengan pengalaman si mufassirnya dengan jalan takwil. ${ }^{6}$ Oleh karena itu, penulis akan mencoba menemukan kolerasi antara makna esoteris dan juga eksoteris yang ada pada teks ayat, sehingga muncullah sebuah kolerasi antara diantara ke dua makna.

Mengenai metode penelitian, maka penelitian ini menggunakan metode sufistikkontekstual yakni pendekatan yang memiliki faedah untuk mengurai sisi esotrik A1Qur'an dengan anggapan bahwa Al-Qur'an memiliki makna dzahir dan makna bațin, ${ }^{7}$ karena adanya petunjuk-petujuk yang tersirat (takwil), ${ }^{8}$ lalu disesuaikan berdasarkan keadaan masa kini. Disertai dengan jenis penelitian kepustakaan (library research) karena penelitian ini mengkaji sumber data dari materi atau literatur yang relevan dengan judul penelitian yang terdapat dalam sumber-sumber pustaka, maka penelitian ini secara khusus bertujuan mengumpulkan data atau informasi dengan bermacammacam materi yang terdapat di ruang perpustakaan. ${ }^{9}$

\section{SEKILAS BIOGRAFI SOLEH DARAT DAN TAFSIR FAIḌUR RAḤMĀN}

KH. Soleh Darat memiliki nama lengkap Muhammad Shalih ibn Umar, lahir di desa Kedung Jombleng, Kecamaan Mayong, Kabupaten Jepara, Jawa Tengah sekitar tahun $1820 \mathrm{M}$. Ada juga yang menyebunya lahir di desa lain. Namun informasi kelahirannya di Desa Kedung Jumbleng lebih kuat daripada di tempat lain. Hal ini diterima dari Kiai Fahur ar-Razi, Kajen, Margoyoso, Pati yang mendapat informasi dari Kiai 'Abd Allah (al-marhum) yang berasal dari satu daerah dengan Muhammad Shalih bin Umar,

${ }^{4}$ Wardatul Azka Eferilia, "Makna Pemasangan Kaligrafi Lafadz Basmalah Di Atas Pintu Rumah Bagi Masyarakat Desa Teluk Limau Kecamatan Gelumbang Kabupaten Muara Enim (Kajian Living Qur'an)" (PhD Thesis, UIN Raden Fatah Palembang, 2020).

${ }^{5}$ Abshor, M. Ulil. "Penafsiran Sufistik Kh. Shalih Darat Terhadap Q.S. Al-Baqarah: 183," Jurnal Studi Ilmu-ilmu Al-Qur'an dan Hadis 19, no. 2 (2019), h. 205.

${ }^{6}$ Muttaqin, Muhamad Zaenal. "Geneologi Tafsir Sufistik Dalam Khazanah Penafsiran AlQur'an," Jurnal Tamaddun : Jurnal Sejarah dan Kebudayaan Islam 7, no. 1 (2019), h. 120.

${ }^{7}$ M. Yunus,Badruzzaman "Pendekatan Sufistik Dalam Menafsirkan Al-Quran," Syifa Al-Qulub 2, no. 1 (2017), h. 2.

${ }^{8}$ Asfar,Khaerul "Tafsir Sufistik (Al-Isyari) Perspektif Teoretis," Al-Wajid: Jurnal Ilmu Al-Quran Dan Tafsir 1, No. 1 (2020), h. 67.

${ }^{9}$ Baidan. Nashruddin Metodologi Penafsiran Al-Quran (Yogyakarta: Pustaka Pelajar, 2016), h. 152 
Dimensi Sosial dalam Tafsir Sufistik

(Penafsiran QS. Al-Fatihah [1]: 1 Oleh KH. Soleh Darat)

yaitu dari Desa Kedung Jumbleng. Beliau wafat di Semarang pada hari Jum'at Legi tanggal 28 Ramadhan 1321 H/18 Desember 1903 dan dimakamkan di pemakaman umum Bergota Semarang. Makamnya banyak diziarahi orang, baik dari Semarang dan sekitarnya maupun dari daerah lain, khususnya pada upacara khaul-nya. ${ }^{10}$

Terlahir pada masa penjajahan, Soleh Darat masih merasakan bagaimana nuansa gelapnya keilmuan Islam di Tanah Nusantara karena larangan mengembangkan ilmu agama oleh penjajah kala itu. Mbah Soleh merupakan putra dari Kiai Umar yang merupakan sosok pejuang dalam perang Jawa (1825-1830) yang dilakukan oleh Pangeran Diponegoro ketika melawan Belanda. Semasa kecilnya Soleh mulai belajar agama dengan ayahnya sendiri. Kemudian, ia melanjutkan perjalanan belajarnya di beberapa Pondok Pesantren di Jawa maupun Mekkah. Ayahnya sendiri mengajak Soleh pergi ke Mekkah setelah ia menyelesaikan pendidikannya di Jawa dengan bersinggah beberapa saat di Singapura. Setelah sampai di Mekkah bergurulah ia dengan beberapa ulama. ${ }^{11}$ Hingga pada akhirnya ia diperbantukan kepada Zain Al-Alim, untuk mengasuh sebuah pesantren di Dukuh Salatiang, Desa Maron Kecamatan Loana, Purworejo. ${ }^{12}$

Selain berstatus sebagai tokoh agama pada masanya Mbah Soleh juga menuliskan beberapa karya. Adapun beberapa karya yang diketahui diantaranya adalah kitab (1) Majmu'asy-Syarī'at al Käfiyat lial- 'Awa;(2) Munjiyat Metik Saking Ihya'Ulumuddin;(3) Lațā'if at-Taharah; (4) Tarjamah Sabīl al- 'Abid 'ala Jauharat at-tauhīd. Dalam karyakaryanya tersebut Mbah Soleh seringkali menggunakan nama Syekh Haji Muhammad Sholeh bin Umar as-Samarani atau semarang sebagaimana tertera di sampul kitabnya. Serta pernah pula Mbah Sholeh menggunakan nama Abu Ibrahim dalam halaman kitab tafsirnya Faid ar-rahman fi Tarjama Tafsīr Kalam Malik ad-Dayyān, dan lain sebagainya. Hal demikian bisa jadi untuk mengenang putra pertamanya, Ibrahim yang tidak ikut serta pulang bersamanya ke Jawa dan menetap di Mekkah. ${ }^{13}$

Salah satu karya yang banyak menjadi objek penelitian adalah tafsirnya Faid arraḥman fì Tarjama Tafsìr Kalam Malik ad-Dayyān. Asal punya usul, tafsir ini ditulis karena keinginan Mbah Soleh dalam menerjemahkan Al-Qur'an ke bahasa Jawa sehingga memudahkan orang-orang awam pada masa itu dalam mempelajari Al-Qur'an, dikarenakan ketika itu masyarakat sekitar tidak bisa bahasa Arab dan salah satu yang turut mendesak Mbah Soleh adalah R.A. Kartini untuk kepada Mbah Soleh agar AlQur'an dapat diterjemahkan untuk menjawab kegelisahnnya, yang berasumsi tidak ada gunanya membaca kitab suci yang tidak diketahui artinya. ${ }^{14}$

Kondisi sulit dalam mengembangkan ajarann Islam saat itu dirasakan oleh Mbah Soleh. Sebab, penjajah Belanda secara resmi melarang, menerjemahkan Al-Qur'an.

${ }^{10}$ Masrur, Mohammad Masrur, "Kyai Soleh Darat, Tafsir Fa'id Al-Rahman Dan Ra. Kartini," At-Taqaddum 4, no. 1 (2016), h. 21-38.

${ }^{11}$ Masrur, h. 24.

${ }^{12}$ Muhammad, Hariyadi and Mukhlis Yusuf Arbi, "Eksposisi Nalar Tafsir Kiai Sholeh Darat; Telaah Transmisi Keilmuan Dan Kontekstualitas Kitab Faidh Ar-Rahman Fi Tarjamah Tafsir Kalam Malik Ad-Dayyan," Al-Burhan Jurnal Kajian Ilmu Dan Pengembangan Budaya Al-Qur'an 19, no. 1 (2019), h. 6.

${ }^{13}$ Hariyadi, Muhammad dan Mukhlis Yusuf Arbi. h. 5

${ }^{14}$ Syahid, Ahmad. "Kontribusi Dan Lokalitas Tafsir Faiḍ Al-Raḥmān.” 14, no. 2 (2020): h. 251. 
Kendati demikian, Mbah Soleh tidak berputus asa. Secara diam-diam ia menerjemahkan ayat Al-Qur'an dengan tulisan huruf "arab gundul" (pegon) agar tidak dicurigai oleh penjajah. Kitab tafsir dan terjemah Al-Qur'an ini diberi nama Faid ar-Rahmān fi Tarjama Tafsīr Kalam Malik ad-Dayyān, merupakan tafsir pertama di Nusantara dalam Bahasa Jawa dengan aksara Arab dan kitab ini pula diihadiahkan kepada RA. Kartini ketika ia menikah dengan R.M. Joyodiningrat, seorang Bupati Rembang. ${ }^{15}$

Kitab ini mulai ditulis pada tanggal 20 Rajab $1309 \mathrm{H}$, selesai ditulis pada tanggal 7 Muharram $1311 \mathrm{H} / 1893 / 94 \mathrm{M}$ dan dicetak pada tanggal 29 Jumadi Al-Akhir tahun $1311 \mathrm{H}$ oleh percetakan Haji Muhammad Amin Singapura. Kitab ini meskipun baru selsai pada jilid pertama Surah Al-Fatihah dan Al-Baqarah, namun cukup tebal. Ada 577 halaman, ditulis dengan huruf Arab Pegon. Selanjutnya pendigitalisasian tafsir ini dilaksanakan pada Agustus 2012 menjelang kegiatan Haul KH. Soleh Darat dan dikerjakan oleh Ikhwan dan Anasom. ${ }^{16}$ Konon, kitab ini terdiri dari 2 jilid, akan tetapi penerbitan jilid ke 2 tidak pernah sampai ke tangan kita. ${ }^{17}$

Jilid pertama, diawali dengan muqaddimah kitab Faị ar-Rahmān fì Tarjama Tafsìr Kalam Malik ad-Dayyān dilanjutkan dengan muqaddimah Surah Al-Fatihah lalu dilanjutkan dengan tafsir Surah Al-Baqarah (penafsiran ayat 1-286) yang juga dimulai dengan muqaddimah Surah Al-Baqarah . Jilid pertama ini mulai ditulis pada Malam Kamis 20 Rajab H/19 Februari 1892 M dan selesai pada Malam Kamis 19 Jumadil Awal 1310 H/9 Desember 1892. Sedangkan jilid ke 2 dimulai dari muqaddimah dari penulis kemudian muqqaddimah Surah Ali Imran dan dilanjutkan dengan tafsir surah An-Nisa' yang dimulai dengan muqaddimah surah an-Nisa' (penafsiran ayat 1-179 surah An-Nisā'). Penulisan jilid 2 ini dselesaikan pada hari Selasa tanggal 17 Safar $1312 \mathrm{H} / 20$ Agustus $1894 \mathrm{M} .^{18}$

Adapun metode penafsiran yang digunakan oleh Mbah Soleh dalam tafsirnya adalah berupa metode tafsir analisis (tahlīlì), yakni sebuah metoode tafsir yang mencoba menjelaskan ayat Al-Qur'an secara analisis, berbagai aspek yang terkait dengan ayat Al-Qur'an dari segi aspek asbab nuzul, munasabah, balaghah, hukum dan lain sebagainya. ${ }^{19}$ Sedangkan ditinjau dari segi corak, maka kitab ini cenderung kepada tasawuf atau bisa disebut corak sufi isyari yang condong menafsirkan ayat-ayat AlQur'an tidak sama dengan makna lahir dari ayat, namun disesuaikan dengan isyaratisyarat yang nampak pada pelaku ritual sufistik dan bisa jadi penafsiran mereka sesuai dengan makna lahir. ${ }^{20}$

Corak sufistik itu dapat terlihat dari penjelasan Mbah Soleh ketika menafsirakan

${ }^{15}$ M. Masrur. Kyai Soleh Daratt, Tafsiir Faid-Al-Rahman dan RA. Kartini. h. 26

16 Darat, Soleh. Muqaddimah Faidh Rahman fi Tarjama Tafsir Kalam Malik ad-Dayyan. Singapura: Haji Muhamma Amin, h. 1311.

${ }^{17}$ Setiawan, Heru "Tafsir Alif Lam Mim Kyai Shalih Darat," Kontemplasi: Jurnal Ilmu-Ilmu Ushuluddin 6, no. 1 (2018). h. 45.

${ }^{18}$ Setiawan, Heru. "Tafsir Alif Lam Mim Kyai Shalih Darat." h. 45.

19 Mustaqim, Abdul. Metodologi Peneleitian Al-Qur'an dan Tafsir (Yogyakarta: Idea Press Yogyakarta, 2015), h. 18.

${ }^{20}$ Syukur, Abdul. "Mengenal Corak Tafsir Al-Qur'an," El-Furqania: Jurnal Ushuluddin Dan Ilmu-Ilmu Keislaman 1, no. 01 (2015), h. 101. 
Dimensi Sosial dalam Tafsir Sufistik

(Penafsiran QS. Al-Fatihah [1]: 1 Oleh KH. Soleh Darat)

ayat dengan menekankan pada ketajaman esoteris atau makna batin dari ayat-ayat Al-Qur'an bersama dengan teks atau makna esksoterik. Dalam judulnya yang bisa diterjemahkan dengan "Pancaran Tuhan Yang Maha Penyayang" istilah dari tasawuf yang mencerminkan irfani epistimologi, didefinisikan sebagai cara untuk memperoleh pengetahuan melalui pembukaan (kashf) dan ilham ketuhanan (ilham). ${ }^{21}$ Adapun alasan penggunaan corak tafsir sufi isyari ini adalah karena tujuan Mbah Soleh ingin mendamaikan konflik epistemik antara kaum fuqaha' yang hanya berorietasi pada makna zahir dan kaum sufi yang hanya berorientasi pada makna batin. ${ }^{22}$

\section{SUFISTIK}

Sufistik merupakan asal kata dari sufi, yang menurut KBBI berarti menunjukkan sifat sufi, beraliran sufi, atau berkaitan dengan ilmu tasawuf. ${ }^{23}$ Sufistik sendiri termasuk dalam kategori sebuah corak penafsiran. Sebagian ulama dapat menyebutnya dengan tafsir sufi atau tafsir isyari. Secara etimologi tafsir isyari yang diambil dari kata ashāra yushīru ishāratan bermakna memberi isyarat atau petunjuk, maka bisa diartikanlah dengan penafsiran Al-Qur'an yang berangkat dari sebuah isyarat atau petunjuk melalui ilham seseorang, dan seseorang yang banyak melalukan ini adalah para ahli tasawuf hingga disebutlah juga dengan nama tafsir sufi. ${ }^{24}$

Sesunguhnya kehidupan sufi sudah terjadi sejak zaman Nabi, namun teori sufi baru ditemukan pada masa setelahnya. Pemaknaan kata tasawuf pun menjadi beragam baik dari segi etimologi maupun terminologi. Ketika dipandang ddari segi definisi etimologi maka pemaknaan kata tasawuf sesuai pada kata dasar yang diambil. Setidaknya ditemukan 4 kata dasar yang menjadi landasan pemaknaan tasawuf diantaranya $a h l$ aș-ṣuffah, șuf, șafi, dan șaf. ${ }^{25}$ Sedangkan ditinjau dari definisi termonologi banyak pula yang telah mengungkapkannnya namun sebagian berpendapat bahwa pada dasarnya merupakan ajaran melatih jiwa agar terbebas dari pengaruh dunia sehingga tercermin akhlak mulia serta dekat dengan Sang Pencipta. ${ }^{26}$

Berangkat dari sebuah pola sikap dan kehidupan (tasawuf) kemudian berkembang sikap itu merasuk kedalam sebuah dialog terhadap ayat Al-Qur'an. Pola tasawuf itu akhirnya juga disandarkan kepada teks-teks Al-Qur'an dan Sunnah Nabi Muhammad. ${ }^{27}$ Hingga muncullah tafsir-tafsir yang condong kepada pola tasawuf. Seperti tafsir Mbah

${ }^{21}$ Mustaqim, Abdul. “The Epistemology of Javanese Qur'anic Exegesis: A Study of Șāliḥ Darat's Fayḍ al-Raḥmān,” Al-Jami'ah: Journal of Islamic Studies 55, no. 2 (2017), h. 361.

${ }^{22}$ Mustaqim, Abdul. “The Epistemology Of Javanese Qur'anic Exegesis.” Al-Jami'ah: Journal of Islamic Studies. h. 358.

23 “KBBI V Online, Https:/Kbbi.Web.Id/ - Penelusuran Google," accessed February 28, 2021, https://www.google.com/search?q=KBBI+V+Online $\% 2 \mathrm{C}+$ https $\% 3 \mathrm{~A} \% 2 \mathrm{~F} \% 2 \mathrm{Fkbbi}$.web. $\mathrm{id} \% 2 \mathrm{~F} \& \mathrm{rlz}=1 \mathrm{C} 1 \mathrm{FHFK}$ idID930ID930\&oq=KBBI+V+Online $\% 2 \mathrm{C}+$ https $\% 3 \mathrm{~A} \% 2 \mathrm{~F} \% 2 \mathrm{Fkbbi}$.web.id \%2F\&aqs=chrome..69i57j0i33312.4697j0j7\&sourceid=chrome\&ie=UTF-8. diakses 24/02/2021.

${ }^{24}$ Said, Muh. "Metodologi Penafsiran Sufistik: Perspektif Al-Gazali," Jurnal Diskursus Islam 2, no. 1 (2014), h. 145.

${ }^{25}$ Hafiun, Muhammad “Teori Asal Usul Tasawuf,” Jurnal Dakwah 13, no. 2 (2012), h. 242.

${ }^{26}$ Hafiun, Muhammad. "Teori Asal Usul Tasawuf.” Jurnal Dakwah. h. 245

27 Ghazali,Abd Moqsith. "Corak Tasawuf Al-Ghazali Dan Relevansinya Dalam Konteks Sekarang," Al-Tahrir: Jurnal Pemikiran Islam 13, no. 1 (2013), h. 70.

138 | Al-Fanar: Jurnal Ilmu Al-Qur'an dan Tafsir 
Soleh Darat, Al-Alusi, Al-Ghazali dan lain sebagainya. Hal itu menunjukkan sebuah perkembangan tasawuf hingga menjadi pola penafsiran bukan hanya praktek kehidupan semata.

Tafsir sufi terbagi menjadi 2 bagian yakni nazariy dan ishāri. Tafsir sufi nazariy adalah tafsir sufi yang dibangun dengan mengungsung dan memperkuat teori-teori mistik yang dianut mufassir dalam memaknai sebuah ayat, sedangkan tafsir sufi isyari lebih kepada menyingkap apa yang ada di dalam makna lahir suatu ayat untuk mengetahui hikmah-hikmahnya dengan pengalaman yang telah di alami oleh sufi. ${ }^{28}$ Di sini terlihat bahwa nazariy lebih mengacu kepada penerapan teori-teori tasawuf, sedangkan jenis ke dua yakni ishāri lebih mengacu kepada pengalaman pribadi sang sufi dalam menentukan sebuah makna ayat.

Dari penjelasan di atas, dapat diketahui adanya perbedaan yang terdapat antara 2 jenis tafsir sufi tersebut. Perbedaan itu juga dijelaskan oleh Husain Adz-Dzahabi dalam kitabnya at-Tafsīr wa al-Mufassirūn. Menurutnya ada 2 sisi perbedaan yang ada yakni; pertama, dari segi dasar landasan dalam menafsirkan ayat, tafsir sufi nazariy berlandaskan dengan teori ilmiah yang muncul dalam hati sang sufi, sedangkan tafsir sufi ishäriy tidak bersandar pada teori-teori ilmiah namun berlandaskan pada latihan kejiwaan yang telah dilalui si sufi; kedua, dari segi pemunculan makna, tafsir sufi nazariy mengeluarkan makna sesuai pada literal ayat dan tidak melihat adanya makna dibalik teks, sedang tafsir sufi ishāriy melihat adanya makna di balik ayat. ${ }^{29}$

\section{PENAFSIRAN SUFISTIK AYAT BASMALAH OLEH SOLEH DARAT}

Tafsiran:

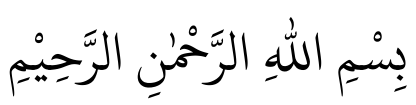

"Tegese solat ingsun kelawan asmane dzate Allah subhanahu wa ta'ala kang persifatan Jalal lan sertane Qohar lan iyo iku madlule Ar-Rahman lan dzat kang persifatan Jamal sertane Kamal lan iyo iku madlule sifat Ar-Rahim. Mongko utawi iki ono iku dadi patang martabat; suwiji martabate asma, kepindo martabate dzat lan iyo lafaz Allah, lan kaping telu martabate Jalal tegese murboweso, lan kaping pat martabate Jamal tegese sempurna. Maka iku isyarah mareng martabat papat Uluhiyah, Ruhaniyah, Samaniyah, lan Hayawaniyah. Maka ono hakikat ma'nane "bismillāhirraḥmānirrahīm" iku setuhune wujude Allah iku kelawan dzat e dewe lan sifat e Allah kabeh iku ono kalane saking arah Jalal lan ono kalane arah Jamal. Maka ngendiko Allah subhanahu wa ta'ala maka kelawan dzat ingsun jumeneng kabeh lan barangkang seenten iku kabeh nama kang maujud kelawan wujud ingsun lan jumeneng kelawan jumeneng ingsun. "Fasubhạna al-ladzi biyadihi malakūtu kulli shain wa ilaihi turja'ūn"

Terjemahan:

"Yakni, aku melaksanakan shalat dengan menyebut nama-Mu Allah subhanahu wa ta'ala yang bersifat Jalan dan Qohhar yang diisyarahi dengan kata ar-Rahman serta sifat Jamal dan Kamal yang diisyarahi dengan kata ar-Rahim. Maka adapun h. 5 .

${ }^{28}$ Yunus, Badruzzaman M. "Pendekatan Sufistik dalam Menafsirkan Al-Quran.” Syifa al-Qulub.

${ }^{29}$ Adz-Dzahabi, Husain. At-Tafsīr wa al-Mufassirūn. Kairo: Maktabah Wahbah. (t.t), h. 261. 
Dimensi Sosial dalam Tafsir Sufistik

(Penafsiran QS. Al-Fatihah [1]: 1 Oleh KH. Soleh Darat)

ini dibagi menjadi 4 martabat yakni martabat asma', martabat dzat yaitu lafaz Allahh, martabat sifat Jalal yaitu sifat Yang Maha Kuasa, dan martabat sifat Jamal yaitu sifat sempurna. Maka itupun berisyarah kepada 4 martabat yakni Uluhiyah, Ruhaniyah, Samaniyah, lan Hayawaniyah. Maka adapun hakikat lafal bismillāhirrạ̣mānirrahīm adalah sesungguhnya Allah ada dengan dzatNya sendiri lan segala sifat Alah itu adakalanya dari segi Jalal dan adakalanya dari segi Jamal. Maka Allah berfirman dengan adanya dzat-Ku maka hadirlah segala yang ada di dunia ini, segala yang ada di dunia ini karena adanya Aku sebagaimana dalil "Fasubhāna al-ladzi biyadihi malakūtu kulli shain wa ilaihi turja'ūn".

Tafsiran:

Utawi "ba" ne bismillah iku "ba tadmin" arane tegese ngawiti ingsun kelawan asma nafsune lan sifat ingsun kabeh mumkin lan kelawan ingsun dadi dhahir sekabehane maujud lan mertikel aken ingsun ing asbabe pengupo jiwone makhluk kabeh kelawan sifat Rahman ingsun lan ngunggahaken ingsun ing derajate wongkang ahli kerabat lan ahli kuramat kelawan sifat Rahim ingsun. Maka dadi ana isyarahe ya iku mareng sekabehane maujud ono maka iyo ikulah dzuhuri Jalal Jamal Allah subhanahu wa ta'ala. Maka ketuduhan setuhuni sifat ar-Rahman lan ar-Rahim iku podo qadim azali lan Allah subhanahu wa ta'ala fil azali wes hadir sifatani (Rahman Rahim).

Terjemahan:

Huruf $b a$ pada lafal bismillah merupakan ba tadmin, musonnef memaknai itu dengan "Aku memulai perbuatanku dengan nama-Mu" dan adannya sifat Allah (Rahman Rahim) menjadi bukti dengan seluruh yang ada di muka bumi ini. Realisasi dari sifat rahman Allah adalah dengan pemberian rezeki kepada seluruh makhluk sedangkan realisasi dari sifat Rahim Allah adalah dengan naiknya derajat orang yang ahli ibadah dan ahli berbuat kebaikan. Maka dari itu, segala yang hadir di muka bumi ini merupakan simbol adanya Allah. Maka diketahuilah bahwa sifat rahman Rahim Allah sudah ada sejak zaman azali.

Tafsiran:

Wes nuturaken Imam Abu Hamid Al-Ghazali setuhuni kanjeng Rasulullah saw iku ngendiko "Takhallaqü bi akhlāqillāh" podo ngengguho siro kabeh kelawan kelakuae Allah saw. Moko seyogyanya keduwe wong mu'min arep nduweni sifat wela asih mareng sak padane maka wajibe melas lan ngasihi iku olehe dewe ndisik. Ora wenang melasi wong liyane yen ora welase awak e dewe Utawi melasi awake iku arep welas rung perkoro suwiji arep welas asih ruhaniyahe lan kepindo arep welas asih jasmanihe. Utawi artine welas asih ruhaniyahe iku arep sempurna olehe ngerekso huquq ar-rububiyyah. Lan artine welas aseh jasmaniyahe iku arep sempurna olehe ngerekso 'ubdiyah. Maka dadi ono sempurna yen manungso iku kamalul ubudiyah, lan kamal ri'ayah huquq arrububiyyah. Maka manungso kang mengkunu iku diarani insan kamil. Maka ono dzuhure "ba bismillah" iku ingdalem insan.

Terjemahan:

Imam Abu Hamid Al-Ghazali berkata sesungguhnya Rasulullah iku bersabda "Takhallaqū bi akhlāqillāh" yang artinya berakhlaklah kalian dengan akhlaknya Allah. Oleh sebab itu sudah selayaknya bagi kaum mukmin untuk memiliki sifat belas kasih kepada ssesama dan belas kasih itu harus dimulai kepada diri sendiri. Adapun berbelas kasih kepada diri sendiri itu ada 2 perkara, pertama berbelas kasih kepada ruhani dan yag keduan berbelas kasih kepada jasamninya.

140 | Al-Fanar: Jurnal Ilmu Al-Qur'an dan Tafsir 
Berbelas kasih kepada ruhaniyah direalisasikan dengan sempurnanya menjaga hak-hak rububiyyah dan maksud dari berbelas kasih kepada jasamani itu dengan sempurnanya menjaga ibadah. Oleh sebab itu, manusia dapat menjadi sempurna ketika dapat menjaga perihal ibadah dan juga ketuhanan dan bisa dikatakan "insan kamil". Maka, nampak penjelasan ba bismillah itu terdapat pada diri manusia.

Tafsiran:

Anapun "alif" e bismillah maka ghaib ora ketingalan mangka ikulah isyarah e dzat Allah Subhanahu wa ta'ala maka ono insan dadi dzahir nya. Maka arah mengkunu matur poro sohabat mareng kanjeng Rasulullah saw ya Rasulullah wonten pundi alif e bismillah maka ngendiko kanjeng Rasulullah saw utawi alif e bismillah iku den colong iblis maka nuli perintah kanjeng Rasulullah purih ndawaaken "ba" ne kelawan bastun ndawaaken isyarah wujude insan kamil wa huwa Muhammad saw maka ikulah isyarahi dawuhi Subhanahu wa ta'ala "wa mā arsalnāka illā rậmatan lil 'àlamīn" wa qāla ta'ala "bi al-mu'minīna raūfur Rahìm”. Lan wus emuji kanjeng Rasulullah saw ing sayyidina Abu Bakar aashshiddiq den puji kelawan pengendikane. Utawi welas asih ummat ingsun mareng ummat ingsun iku Abu Bakar Ash-Shiddiq. Fal hasil alif e isyarah mareng dzat Allah bila mitsal wa bila kayf. Lan ba ne isyarah mareng Muhammad saw wa rafa'nā laka dzikrak. Maka tatkalane ono manungso kabeh iku ora ono podo biso muji ing Allah subhanahu wa ta'ala kelawan puji tsana. Lan ora kuasa kelawan puji syukur. La ora kuasa muji kelawan puji madh, maka dadi ngendiko Allah subhanahu wa ta'ala ... "Alhamdulillah".

Terjemahan:

"Huruf alif pada lafal bismillah tidak nampak mengisyaratkan itulah dzat Allah dan adanya manusia sebagi bukti bahwa Allah itu ada. Oleh karena hal itu,para sahabat pun bertanya kepada Nabi saw 'Wahai Nabi dimanakah huruf alif bismillah?" Nabi saw menjawab "Sesungguhnya alif bismillah telah dicuri oleh iblis", maka kemudian Nabi saw memerintahkan untuk tidak memanjangkan huruf $b a$ sebagai isyarah bahwa adanya insan kamil yaitu Nabi Muhammmad saw. Hal itu pun menjadi isyarah adanya firman Allah 'wa mā arsalnāka illā rahmatan lil 'àlamìn' dan firman Allah 'bi al-mu'minina raūfur Raḥim'. Kesimpulannya, bahwa alif bismillah berisyarah adanya dzat Allah tanpa ada serupa dan cara. Sedangkan huruf $b a$ isyarah kepada Nabi Muhammad sebagaimmana firman ' $w a$ rafa'nā laka dzikrak'. Maka tatkala ada manusia yang tidak sanggup memuji Allah dengan puji tsana, tidak kuasa memuji dengan puji syukur, dan tidak kuasa memuji denga puji madh, maka Allah kemudian berfirman 'Alhamdulillah'.'

Penafsiran di atas memuat beberapa point penjelasan. Sebagaimana hasil pengamatan penulis, terdapat 3 point pembahasan yakni huruf " $b a$ " dan "alif", pembahasan kata ism, dan pembahasan dua sifat Allah. Ketiga pembahasan tersebut disuguhkan dengan bentuk yang sedikit ringkas namun juga tidak meninggalkan kutipan-kutipan dalil dari selainya, baik itu dalil Al-Qur'an maupun pendapat ulama lain yang mempertegas pernyataanya. Penjelasan yang juga mengeluarkan makna bathiniyyah ini menjadi sebuah ciri khas yang ada dalam tafsirnya. Di dalam pendapatnya sering mengungkapkan kata "isyarat" hal itu menunjukkan adanya sebuah andil makna batin yang dikeluarkan oleh pengarang.

Ketika dipandang dari segi makna literal ayat maka penulis dapati bahwa ayat di atas merupakan anjuran untuk menyertakan nama Allah ketika seseorang ingin melakukan 
Dimensi Sosial dalam Tafsir Sufistik

(Penafsiran QS. Al-Fatihah [1]: 1 Oleh KH. Soleh Darat)

sesuatu. Anjuran tersebut tersirat dalam penjelasan makna huruf " $b a$ " oleh Mbah Soleh. ${ }^{30}$ Di samping makna tersebut, Mbah Soleh juga menuturkan bahwa hakikatnya, lafal bismillah menunjukkan bahwa segala yang hadir di muka bumi ini merupakan simbol adanya Allah. ${ }^{31}$ Hal ini bertujuan untuk menjelaskan kehidupan di dunia ini terjadi karena adanya sosok Tuhan Sang Pencipta.

Nuansa sufitik pun terasa dalam penafsiran basmalah oleh Mbah Soleh. Karena sejatinya penafsiran sufistik itu mengeluarkan makna-makna yang dihasilkan dari ayat-ayat Al-Qur'an yangmana tidak diperoleh dari bunyi ayat, namun dari kesan yang ditimbulkan oleh lafaz dalam benak penafsir yang memiliki kebersihan hati serta pikiran tanpa adanya meniadakan makna literal ayat yang dibahas. ${ }^{32}$ Hal itu nampak dari pernyataan Mbah Soleh yang mengungkapkan makna-makna di luar teks ayat. Pendapatnya mengenai segala yang hadir di muka bumi ini merupakan simbol adanya Allah, ${ }^{33}$ mencerminkan perintah untuk memulai segala sesuatu dengan basmalah tidak hanya karena agar perbuatan itu menjadi baik, indah, benar, terhindar dari godaan nafsu, atau doronngan ambisi dan kepentingan pribadi, ${ }^{34}$ namun juga mengingatkan bahwa setiap diri manusia beserta perbuatannya dapat terjadi karena adannya Sang Pencipta. Sehingga sudah sepatutya sebagai seorang makhluk kita melaksanakan segala sesuatu sesuai dengan aturan penciptanya karena sejatinya kita tidak dapat terlepas dari pengawasan-Nya.

Dialog antara makna literal ayat dan makna bathiniyah juga terlihat dalam pembahasan dua sifat Allah. Dua sifat yang menyertai lafaz Allah berupa Rahman Rahim ditafsiri sebagai sifat yang juga harus dimiliki oleh manusia. Dalil berupa ungkapan Imam Al-Ghazali yang dikutip Mbah Soleh berupa perintah mengikuti akhlak seperti akhlak Allah bagi para manusia, ${ }^{35}$ menekankan adanya suatu perintah bahwa kita sebagai makhluk Allah untuk bisa memahami dan mensyukuri anugerah yang telah diberikan dengan cara berbuat yang sedemikian kepada sesamanya. Karena yang dibahas dalam ayat basmalah adalah sifat kasih sayang, maka sifat itulah yang harus kita tanam dan dibagikan kepada manusia lainnya.

Penulis menemukan adanya kolerasi antara manusia dan Tuhannya dalam hal sifat. Hubungan itu terjadi karena adanya ruh ciptaan Allah yang ditiupkan dalam diri manusia sebagaimana dalil QS. Al-Hijr [15]: 29. Sehingga titisan sifat tuhan berada dalam diri manusia. Atas dasar hal itu, dapat diketahui bahwa sejatinya makhluk sebagai simbol adanya Sang Pencipta karena ruh-ruh juga berada dalam diri manusia. Pernyataan itu juga termuat dalam penafsiran Mbah Soleh yang mengatakan bahwa

${ }^{30}$ Darat, Soleh, Faị̣ ar-Rahmān fi Tarjama Tafs̄̄r Kalam Malik ad-Dayyān. (Singapura: Haji Muhamma Amin. 1311), h. 6.

${ }^{31}$ Darat, Soleh, Faị̣ ar-Rahmān fi Tarjama Tafsīr Kalam Malik ad-Dayyān. h. 6.

${ }^{32}$ Madid,Izzul. "Tafsir Sufi; Kajian Atas Konsep Tafsir Dengan Pendekatan Sufi," Jurnal Wasathiyah 2, no. 1 (2018), h. 145.

${ }^{33}$ Darat, Soleh, Faị̣ ar-Rahmān fì Tarjama Tafsīr Kalam Malik ad-Dayyān, h. 6.

${ }^{34}$ Shihab, Moh. Quraish. Tafsir al-Misbah: pesan, kesan dan keserasian Al-Qur'an (Jakarta: Lentera Hati, 2009), h. 24.

${ }^{35}$ Darat, Soleh, Faị ar-Rahmān fì Tarjama Tafsīr Kalam Malik ad-Dayyān. h. 6. 
manusia seyogyanya berakhlak sebagaimana akhlak tuhannya ${ }^{36}$ dan dalam pembahasan basmalah maka yang harus dimiliki manusia adalah sifat belas kasih, baik kepada diri sendiri dan juga lingkungan sekitarnya.

Berasal dari asal kata yang sama yaitu rahima secara bahasa dapat diartikan dengan kandungan, mengasihani, mrahmati, menyayanngi. ${ }^{37}$ Kemudian ditulis dengan bentuk Rahman menunjukkan kepada sifat perbuatan yang di dalamnya memuat unsur mubālaghah (melebih-lebihkan) kepada sifat yang sementara, sedang Rahim menunjukkan kepada sifat perbuatan yang di dalamnya menunjukkan unsur mubālaghah (melebih-lebihkan) namun kepada sifat yang kekal dan tetap. ${ }^{38}$ Sehingga dapat penulis pahami bahwa sifat Rahman direalisasikan di dunia dan sifat Rahim direalisasikan ketika di akhirat.

Pemilihan dua sifat Rahman Rahim menimbulkan sebuah pertanyaan, mengapa kedua sifat tersebut yang digunakan, sementara masih ada sifat-sifat Allah yang lain. Quraisy Syihab dalam tafsirnya berpendapat bahwa kedua sifat ini dipilih karena sifat yang paling dominanm seperti yang tersebutkan dalam Al-Qur'an QS. Al-A'raf [7]: 156 "Rahmat-Ku mencakup segala sesuatau”. ${ }^{39}$ Selain menjadi sifat dominan, menurut penulis adanya sifat tersebut karena sifat kasih sayang tersebut juga sifat yang tumbuh dalam diri manusia. Melihat dari penafsiran Mbah Soleh mengenai dua sifat tersebut beserta kaitan adanya huruf " $b a$ " yang memuat makna tadmin (menyatukan), maka penulis menemukan adanya hubungan antara sifat yang disebutkan dengan asal usul penciptaan manusia yakni berstatus sebagai hamba namun juga makhluk sosial yang selalu membutuhkan bantuan orang lain.

Mbah Soleh menjelaskan bahwa realisasi sifat Raḥmān Allah dapat berupa pemberian rezeki kepada seluruh makhluk sedangkan sifat Rahìm adalah dengan naiknya derajat orang yang ahli ibadah dan ahli berbuat kebaikan. ${ }^{40}$ Pendapat lain juga mengatakan bahwa kata Rahmōn adalah sifat kasih sayang Allah yang berorientasi kepada kehidupan duniawi sedang Rahìm beriorientasi pada kehidupan ukhrowi. ${ }^{41}$ Sehingga dapat diketahui sifat Rahmmān bersifat global dan dicurahkan kepada semua makhluk ciptaan-Nya di dunia baik yang berakal seperti manusia ataupun tidak berakal seperti tumbuhan hewan, dan lain sebagainya. Semua akan mendapatkan kasih sayangNya terbukti dengan cukupnya kebutuhan hidup mereka. Sedangkan Rahìm bersifat lebih khusus dan hanya diberikan kepada orang muslim. Kasih sayang Allah di akhirat

${ }^{36}$ Darat, Soleh, Faị̣ ar-Rahmān fì Tarjama Tafsīr Kalam Malik ad-Dayyān. h. 6.

37 "Kamus Online Arab Indonesia Almaany, Https:/Www.Almaany.Com/Id/Dict/Ar-Id/ Arab-Ke-Indonesia/ - Penelusuran Google," accessed February 28, 2021, https://www.google. $\mathrm{com} / \mathrm{search} ? \mathrm{q}=\mathrm{Kamus}+\mathrm{Online}+\mathrm{Arab}+$ Indonesia+Almaany\%2C+https\%3 A\%2F\%2Fwww.

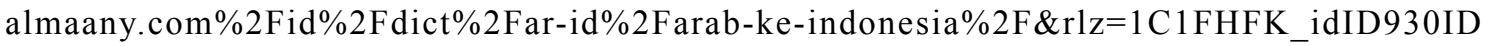
930\&oq $=$ Kamus + Online + Arab + Indonesia + Almaany $\% 2 \mathrm{C}+\mathrm{https} \% 3 \mathrm{~A} \% 2 \mathrm{~F} \% 2 \mathrm{Fwww}$.almaany. com $\% 2$ Fid $\% 2$ Fdict $\% 2$ Far-id\%2Farab-ke-indonesia $\% 2 F \& a q s=$ chrome..69i57.3018j0j7\&sourceid=c hrome\&ie $=$ UTF-8., diakses 25/02/2021

${ }^{38}$ Muhyiddin ad-Duruwaisy. I'robul Qur'an al-Karim Wa Bayanuhu. (Beirut: Dar al-Yamamah wa Dar Ibn Katsir. Jil. 1. Cet. 7. 1999), h. 24.

${ }^{39}$ Shihab, Moh. Quraish. Tafsir al-Mishbah: pesan, kesan dan keserasian Al-Qur'an. h. 21.

${ }^{40}$ Darat, Soleh, Faị ar-Rahmān fì Tarjama Tafsīr Kalam Malik ad-Dayyān. h. 6.

${ }^{41}$ Syihab, Moh. Quraisy ,Tafsir Al-Mishbah. h. 22. 
Dimensi Sosial dalam Tafsir Sufistik

(Penafsiran QS. Al-Fatihah [1]: 1 Oleh KH. Soleh Darat)

kelak hanya akan didapat oleh para makhluk yang mengabdi kepada-Nya.

\section{NILAI SOSIAL DALAM AYAT BASMALAH}

Nilai sosial terbentuk dari 2 kosa kata yakni nilai dan sosial. Menurut KBBI nilai bisa diartikan sebuah harga, angka kepandaian, banyak sedikitnya isi, sifat-sifat (hal-hal) yang penting atau berguna bagi kemanusiaan dan sesuatu yang menyempurnakan manusia sesuai dengan hakikatnya, sedangkan sosial dapat diartikan dengan sesuatu yang berkenaan dengan masyarakat. Melihat nilai disandarkan kepada lafal sosial maka dapat kita simpulkan bahwa nilai sosial adalah sifat-sifat penting atau berguna dalam lingkung kemasyarakatan.

Definisi di atas membentuk sebuah pemahaman bahwa nilai sosial dapat terbentuk manakala terjadi hubungan antara individu yang satu dengan individu yang lain. Manusia diciptakan sebagai makhluk yang tidak dapat berdiri sendiri menjadikannya sebagai makhluk yang selalu membutuhkan orang lain dan dapat disebut dengan makhluk sosial. ${ }^{42}$ Hubungan timbal balik yang terjadi sesama manusia akan membentuk nilainilai yang di dalamnya bisa saja sebuah nilai positif dan juga negatif, bisa saja diterima ataupun ditolak. Oleh sebab itu, nilai sosial bergantung bagaimana proses sosial yang terjadi yakni ketika dalam masa berinteraksi sosial.

Ungkapan basmalah yang telah diterapkan oleh sebagian orang dalam kehidupan bermasyarakat menjadi sebuah simbol terdapatnya pengaruh basmalah dalam pola pikir seeorang ketika menggunakan atau mengucapkan ungkapan tersebut. Keyakinan mengenai manusia yang tidak dapat terlepaskan dari Sang Pencipta merupakan faktor utama bagaimana seseorang dapat yakin menggunakan ungkapan basmalah yang merupakan salah satu potongan ayat dalam Al-Qur'an. Hal itu dapat terjadi karena manusia sebagai seorang mahkluk tidak akan mampu melepaskan diri dari kuasa Sang Penciptanya disertai dengan adanya Al-Qur'an merupakan kalam Allah, berkedudukan sebagai perantara dalam ketentuan atau aturan Allah. Di samping itu, kesadaran diri yang tidak pula mampu melepaskan diri dari tatanan masyarakat menuntut adanya hubungan baik antara sesama, dengan cara berbagi kenikmatan kepada sesama.

Kembali melihat pada penafsiran Mbah Soleh, penulis menemukan adanya nilai sosial yang bersifat positif di dalamnya. Hal itu tersirat dari perintah untuk saling mengasihi antara sesama manusia. Sifat Pengasih dan Penyayang yang pada hakikatnya adalah milik Allah ditafsirkan dengan sifat yang juga harus ada pada diri manusia. Jika dikaitkan dengan asal usul penciptaan, maka dapat kita ketahui bahwa manusia memuat unsur ruh Allah. Sebagaimana yang disebutkan dalam QS. As-Sajdah [32]: 9. Oleh sebab itu, adanya setiap sifat manusia merupakan titisan dari sifat Tuhannya.

Secara dzahir ayat, tidaklah tampak bahwa kedua sifat tersebut ditujukan kepada makhluk Allah. Sebab, dipandang dari susunan kalimat ayat maka kedua sifat tersebut mensifati lafal Allah yangmana memiliki orientasi praktek yang berbeda. Sebagian pendapat mengatakan bahwa orientasi sifat Raḥmān adalah berada pada kehidupan

${ }^{42}$ Kaswadi,Dela Ayu, Eko Wulandari, and Anita Trisiana, "Pentingnya Komunikasi Sosial Budaya Di Era Globalisasi Dalam Perspektif Nilai Pancasila," Jurnal Global Citizen: Jurnal Ilmiah Kajian Pendidikan Kewarganegaraan 6, no. 2 (2019), h. 64.

144 | Al-Fanar: Jurnal Ilmu Al-Qur'an dan Tafsir 
sementara yakni dunia, sedangkan Rahim diorientasikan pada kehidupan kekal yakni akhirat. ${ }^{43}$ Adanya belas kasih Allah ketika di dunia bersifat mutlak bagi semua makhlukNya, sementara belas kasih yang diberikan oleh Allah ketika di akhirat dikhususkan bagi orang-orang yang bertakwa kepada Allah.

Allah Swt. merealisasikan sifat Rahmmān dengan memberikan rezeki kepada para makhluk ciptaan-Nya dan sifat Rahìm dengan mengangkat derajat ahli ibadah. ${ }^{44}$ Mengkiyaskan dari gambaran yang diungkapkan, maka manusia dapat merealisasikan sifat Rậmān Raḥim dengan berbagi rezeki kepada yang membutuhkan seperti membayar zakat, bersedekah, atau bahkan memberi hadiah, serta saling menolong dalam kebaikan seperti saling mengingatkan dalam hal kebaikan agar dapat selalu bertakwa kepada Sang Pencipta. Hal itu dilakukan sebagaimana ajaran Islam yang telah tertera dalam Al-Qur'an.

Mbah Soleh menambahkan bahwa manusia seyogyanya berbelas kasih kepada diri sendiri terlebih dahulu sebelum mempraktekkannya kepada sesama. Menyadari asal usul kejadian manusia adalah makhluk 2 dimensi yakni dimensi ruh dan jasad sebagaimana dalam QS. as-Sajdah [32]: 9, maka penerapan belas kasih harus berada pada dua dimensi tersebut. Menurut Mbah Soleh realisasi belas kasih kepada ruhaniy dapat dengan cara menjaga hak-hak Ketuhanan sedangkan berbelas kasih pada jasadiyah dengan cara menjaga hak-hak ibadah. ${ }^{45}$

Manusia yang diciptakan dengan status seorang hamba sebagaimana dalam QS. adz-Dzariyat [51]: 56, budak dari tuannya, menjadikan hamba tidak dapat terlepaskan dari segala aturan yang telah ditentukan oleh tuannya. Hal itu menunjukkan adanya hubungan yang erat pada keduanya. Sedang manusia sebagai makhluk sosial seperti yang tercantum dalam QS. al-Hujurat [49]: 13 memberikan sebuah pertanda keterkaitannya makhluk di muka bumi. Jika dipahami, maka menjaga hak Tuhan itu adalah menjaganya seorang terhadap hubungan menuju Tuhannya, sedangkan menjaga hak ibadah adalah menjaganya seseorang terhadap hubungan antar sesamanya. Di sinilah digambarkannya nilai sosial yang ada.

Pada akhirnya, penulis menyimpulkan bahwa dua sifat yang disebutkan dalam ayat bismillah dalam tafsir Mbah Soleh tidak hanya menjelaskan tentang sifat Allah namun juga sifat manusia dalam berinteraksi. Saling mengasihi dengan cara berbagi rezeki dan saling mengingatkan dalam kebaikan merupakan nilai sosial positif yang dapat tergambarkan. Tanpa meniadakan bahwa Allah Sang Maha Pengasih lagi Maha Penyayang, sebagai manusia yang taat sudah sepatutnya kita juga berlaku dengan sifatsifat yang dimiliki oleh-Nya. Meski tidak dapat disamakan antara makluk dan tuannya akan tetapi menapak tilas kepada sifat sang tuan termasuk salah satu yang dianjurkan, sebagaimana yang telah diterangkan oleh Mbah Soleh pada paragraf sebelumnya.

\section{PENUTUP}

KH. Soleh Darat merupakan salah satu mufassir Indonesia yang hidup kurang lebih

\footnotetext{
${ }^{43}$ Syihab, Moh. Quraisy. Tafsir Al-Misbah, h. 22.

${ }^{44}$ Darat, Soleh, Faị̀ ar-Rahmān fì Tarjama Tafsīr Kalam Malik ad-Dayyān, h. 6.

${ }^{45}$ Darat. Soleh Faị̣ ar-Rahmān fì Tarjama Tafsīr Kalam Malik ad-Dayyān, h. 7.
} 
Dimensi Sosial dalam Tafsir Sufistik

(Penafsiran QS. Al-Fatihah [1]: 1 Oleh KH. Soleh Darat)

pada abad ke-19 M. Tokoh ulama yang turut berkontribusi dalam pemaknaan AlQur'an, dilihat dari karyanya berupa kitab tafsir yang berjudul Faidh ar-Rahman $f$ Tarjama Tafsir Kalam Malik ad-Dayyan (ditulis pada 1892 M dan selesai pada 1893/94 M). Tafsir ini merupakan tafsir yang tumbuh di kawasan Jawa (Semarang). dicetak pada tanggal 29 Jumadi Al-AKhir tahun $1311 \mathrm{H}$ oleh percetakan Haji Muhammad Amin Singapura. Kitab ini meskipun baru selsai pada jilid pertama Surah Al-Fatihah dan Al-Baqarah, namun cukup tebal yakni ada 577 halaman, ditulis dengan huruf Arab Pegon. Selanjutnya pendigitalisasian tafsir ini dilaksanakan pada Agustus 2012 menjelang kegiatan Haul KH. Soleh Darat dan dikerjakan oleh Ikhwan dan Anasom. Terdiri dari 2 jilid, jilid pertama penafsiran Surah Al-Fatihah-Surah Al-Baqarah dan jilid kedua berupa penafisiran lanjutan dr jilid pertama-Surah An-Nisa. Kitab ini menggunakan metode tafsir tahlili dan bercorak fiqh serta tasawuf/isyari.

Dalam tafsiran Mbah Soleh QS. Al-Fatihah [1]: 1 menyiratkan sebuah pemahaman bahwa dua sifat yang tercantum dalam ayat bismillah yakni Rahman Rahim merupakan sifat Allah sekaligus sifat yang harus dimiliki oleh para makhluk-Nya. Kedua sifat tersebut pun mengandung sebuah nilai sosial ketika diterapkan dalam diri manusia. Pasalnya, dengan adanya sifat Rahman Rahim manusia akan mencerminkan sikap saling membantu kepada sesama. Realisasi sifat tersebut dapat berupa saling berbagi rezeki kepada yang tidak mampu dan saling menasihati dalam kebaikan agar tetap berada dalam ketakwaan.

\section{DAFTAR PUSTAKA}

Abshor, M. Ulil. "Penafsiran Sufistik KH. Shalih Darat Terhadap QS. Al-Baqarah: 183." Jurnal Studi Ilmu-ilmu Al-Qur'an dan Hadis 19, no. 2, 2019.

Asfar, Khaerul. "Tafsir Sufistik (Al-Isyari) Perspektif Teoretis." Al-Wajid: Jurnal Ilmu Al-Quran dan Tafsir 1, no. 1, 2020.

Ashani, Sholahuddin. "Tafsir Huruf Ba' Dalam Basmalah; Pendekatan Tafsir Isyari Najmuddin Al-Kubra" 6. 1, 2020.

Azhari, Fathurrahman. "Ikhtilaf Ulama Tentang Kedudukan Basmalah Dalam Al-Fatihah Dibaca Ketika Shalat.” Syariah Jurnal Hukum dan Pemikiran 15, no. 2, 2016.

Azka, Eferilia Wardatul. "Makna Pemasangan Kaligrafi Lafadz Basmalah Di Atas Pintu Rumah Bagi Masyarakat Desa Teluk Limau Kecamatan Gelumbang Kabupaten Muara Enim (Kajian Living Qur'an)." PhD Thesis, UIN Raden Fatah Palembang, 2020.

Baidan, Nashruddin, Metodologi Penafsiran Al-Quran, Yogyakarta: Pustaka Pelajar, 2016.

Darat, Soleh, Faị ar-Rahmān fi Tarjama Tafsīr Kalam Malik ad-Dayyān, Singapura: Haji Muhammad Amin, 1311.

Ad-Duruwaisy, Muhyiddin. I'robul Qur'an al-Karim Wa Bayanuhu. Beirut: Dar alYamamah wa Dar Ibn Katsir. Jil. 1, Cet. 7, 1999.

Adz-Dzahabi, Husain, At-Tafsir wal Mufassirun. Kairo: Maktabah Wahbah. (t.t). 
Ghazali, Abd Moqsith. "Corak Tasawuf Al-Ghazali Dan Relevansinya Dalam Konteks Sekarang." Al-Tahrir: Jurnal Pemikiran Islam 13, no. 1, 2013.

Hafiun, Muhammad. “Teori Asal Usul Tasawuf.” Jurnal Dakwah 13, no. 2, 2012.

Hamka, Tafsir Al-Azhar. Singapura: Pustaka Nasioanal PTE LTD, 1982.

Hariyadi, Muhammad, and Mukhlis Yusuf Arbi. "Eksposisi Nalar Tafsir Kiai Sholeh Darat; Telaah Transmisi Keilmuan Dan Kontekstualitas Kitab Faidh Ar-Rahman Fi Tarjamah Tafsir Kalam Malik Ad-Dayyan.” Al-Burhan| Jurnal Kajian Ilmu Dan Pengembangan Budaya Al-Qur'an 19, no. 1, 2019.

"Kamus Online Arab Indonesia Almaany, Https://Www.Almaany.Com/Id/Dict/ Ar-Id/Arab-Ke-Indonesia/ - Penelusuran Google." Accessed February 28, 2021. https://www.google.com/search?q=Kamus+Online+Arab+Indonesia + Almaany $\% 2 \mathrm{C}+$ https $\% 3 \mathrm{~A} \% 2 \mathrm{~F} \% 2 \mathrm{Fwww}$.almaany.com $\% 2 \mathrm{Fid} \% 2 \mathrm{Fdict} \% 2 \mathrm{Far}-$ id\%2Farab-ke-indonesia\%2F\&rlz=1C1FHFK_idID930ID930\&oq=Kamus + Online + Arab + Indonesia + Almaany $\% 2 \mathrm{C}+\mathrm{https} \% 3 \mathrm{~A} \% 2 \mathrm{~F} \% 2 \mathrm{Fwww}$.almaany. com $\% 2$ Fid $\% 2$ Fdict $\% 2$ Far-id $\% 2$ Farab-ke-indonesia\%2F\&aqs=chrome..69i57.30 $18 \mathrm{j} 0 \mathrm{j} 7 \&$ sourceid $=$ chrome\&ie $=\mathrm{UTF}-8$.

Kaswadi, Dela Ayu, Eko Wulandari, and Anita Trisiana. "Pentingnya Komunikasi Sosial Budaya Di Era Globalisasi Dalam Perspektif Nilai Pancasila." Jurnal Global Citizen: Jurnal Ilmiah Kajian Pendidikan Kewarganegaraan 6, no. 2, 2019.

“KBBI V Online, Https://Kbbi.Web.Id/ - Penelusuran Google.” Accessed February 28, 2021. https://www.google.com/search?q=KBBI+V+Online $\% 2 \mathrm{C}+$ https $\% 3 \mathrm{~A} \% 2 \mathrm{~F}$ $\% 2 F k b b i . w e b . i d \% 2 F \& r l z=1 C 1 F H F K$ idID930ID930\&oq $=$ KBBI $+\mathrm{V}+$ Online $\% 2$ $\mathrm{C}+\mathrm{https} \% 3 \mathrm{~A} \% 2 \mathrm{~F} \% 2 \mathrm{Fkbbi.web.id} \% 2 \mathrm{~F} \& \mathrm{aqs}=$ chrome..69i57j0i33312.4697j0j7\& sourceid $=$ chrome\&ie $=U$ TF -8 .

Madid, Izzul. "Tafsir Sufi; Kajian Atas Konsep Tafsir Dengan Pendekatan Sufi.” Jurnal Wasathiyah 2, no. 1, 2018.

Masrur, Mohammad. "Kyai Soleh Darat, Tafsir Fa'id Al-Rahman Dan Ra. Kartini.” AtTaqaddum 4, no. 1, 2016.

Mustaqim, Abdul, Metodologi Peneleitian Al-Qur'an dan Tafsir Yogyakarta: Idea Press Yogyakarta, 2015.

, “The Epistemology of Javanese Qur'anic Exegesis: A Study of Șālih Darat's Fayḍ al-Raḥmān.” Al-Jami'ah: Journal of Islamic Studies 55, no. 2, 2017.

Muttaqin, Muhamad Zaenal. "Geneologi Tafsir Sufistik Dalam Khazanah Penafsiran Al-Qur'an." Jurnal Tamaddun : Jurnal Sejarah dan Kebudayaan Islam 7, no. 1, 2019.

Said, Muh. "Metodologi Penafsiran Sufistik: Perspektif Al-Gazali." Jurnal Diskursus Islam 2, no. 1, 2014.

Setiawan, Heru. "Tafsir Alif Lam Mim Kyai Shalih Darat." Kontemplasi: Jurnal IlmuIlmu Ushuluddin 6, no. 1, 2018.

Shihab, Moh. Quraish. Tafsir al-mishbah: pesan, kesan dan keserasian al-Qur'an. Jakarta: Lentera Hati, 2009.

Syahid, Ahmad. "Kontribusi Dan Lokalitas Tafsir Faị̣ Al-Raḥmān.” 14, no. 2, 2020. 
Dimensi Sosial dalam Tafsir Sufistik

(Penafsiran QS. Al-Fatihah [1]: 1 Oleh KH. Soleh Darat)

Syukur, Abdul. "Mengenal Corak Tafsir Al-Qur'an." El-Furqania: Jurnal Ushuluddin Dan Ilmu-Ilmu Keislaman 1, no. 01, 2015.

Yunus, Badruzzaman M. "Pendekatan Sufistik Dalam Menafsirkan Al-Quran.” Syifa AlQulub 2, no. 1, 2017.

148 | Al-Fanar: Jurnal Ilmu Al-Qur'an dan Tafsir 